\title{
Sobre algunos vínculos entre la ciencia antropológica y los derechos humanos*
}

\author{
About some ties \\ between anthropological science \\ and human rights
}

\author{
ESTEBAN KROTZ**
}

\begin{abstract}
The article demonstrates the intrinsic similarity between the tradition offormulation of human rights, their worldwide promotion, and the defense of the victims of human rights violations of human rights, on one hand, with anthropology, the scientific study of humanity, specializing in inventory and explaining world's sociocultural diversity, on the other. To this end, the existence of the same two theoretical aspects in both traditions of thinking will be first established: the tension between the local and the global, and their essentially processual character. Against this background, then, utopian elements, which can be found in both cultural currents, will be approached. The final short reflection refers to the existence of this subject matter in universities with anthropology departments.
\end{abstract}

Key words: anthropology of human rights, relativism-universalism, processuality in human rights and anthropology, anthropology and Utopia

\begin{abstract}
Resumen
El artículo evidencia la semejanza intrínseca entre la tradición de la formulación de los derechos humanos, su promoción planetaria y la defensa de las víctimas de su violación y la antropología, ciencia humana especializada en inventariar y explicar la diversidad sociocultural del mundo. Para ello, se muestra primero la presencia de los mismos aspectos teóricos en ambas tradiciones de pensamiento, a saber: la tensión entre lo local y lo global, y su carácter esencialmente procesual. Ante este trasfondo se abordan en seguida, de modo específico, los elementos de tipo utópico que se hallan en las dos corrientes culturales. El comentariofinal hace una breve referencia a la presencia de esta temática en las universidades en las que se enseña antropología. Palabras clave: antropología de los derechos humanos, relativismo-universalismo, procesualidad en derechos humanos y antropología, antropología y utopía
\end{abstract}

\footnotetext{
* Artículo recibido el 05/02/21 y aceptado el 19/05/21.

** Universidad Autónoma Metropolitana-Iztapalapa, Departamento de Antropología. Av. San Rafael Atlixco núm. 186, col. Vicentina, alcaldía Iztapalapa, 09340 Ciudad de México <krotz@xanum.uam.mx>.
} 
Hay que mirar el mundo como una tarea, como un modelo, como un intento para el que no hay ejemplos conocidos que seguir... Vivimos rodeados de posibilidades y no únicamente de cosas que existen.

Ernst Bloch, "Fragmentos sobre la utopía"

\section{Introducción: contextos y objetivo}

$\mathrm{L}$ a preparación y la realización del coloquio sobre "el quehacer antropológico en la búsqueda y construcción de la paz y la justicia" ${ }^{1}$ han estado desarrollándose en el contexto de una aguda y creciente crisis que bien podríamos llamar civilizatoria. Esto tal vez suene exagerado, pero la lista de situaciones globales y locales -algunas de las últimas como causas de las primeras, pero también algunas de las primeras como causas de las últimas- que constituyen sus manifestaciones es larga, y fácilmente podría alargarse más: los efectos del cambio climático antropogénico; las consecuencias aún virulentas del colapso socioeconómico iniciado en 2007-2008 a causa de una tan planetaria como salvaje especulación financiera; la debilidad del modelo republicano clásico puesto en evidencia tanto por los gobiernos actuales de Estados Unidos, Brasil, Rusia y China como por la incapacidad de la Unión Europea de obligar a sus miembros a respetar las normas democráticas fundamentales; las inestabilidades sociales reveladas en unos lugares del mundo y luego reproducidas en otros muy distantes por cantidades cada vez mayores de migrantes desesperados en todos los continentes; el incremento de la influencia económica, social y política sin control de un grupúsculo de consorcios transnacionales cada vez más gigantes, e igualmente del llamado crimen organizado en todo el mundo; la utilización de las redes digitales como mecanismos de control ideológico y político por empresas privadas y aparatos estatales; las muchas caras de la lacerante desigualdad socioeconómica cuyo número parece multiplicarse en vez de disminuir...

¿No viene aquí a la mente la voluminosa obra colegiada ideada y organizada durante varios años por la antropóloga chiapaneca Xochitl Leyva Solano para promover y reforzar una perspectiva "sureada", colaborativa e intercultural en las antropologías latinoamericanas? Su subtítulo define la situación vigente como "entre crisis, entre guerras", ${ }^{2}$ mientras que el antropólogo colombiano Arturo Escobar señala en su "Presentación" que de nuevo se plantean;

preguntas que se hacen cada vez más acuciantes, aunque la academia "normal" no se dé aún por enterada de su importancia para la construcción del conocimiento: ¿con quién, cómo y desde dónde pensamos? ¿Con qué propósitos? ¿Qué significa pensar con otros -con los activistas de los movimientos que producen sus propios conocimientos, con los subalternos, con los grupos sociales en resistencia- en vez de pensar solamente desde, y con, los cánones de las ciencia sociales, por críticas que éstas parezcan? [Escobar, 2018: 9]. ${ }^{3}$

Como puede verse con facilidad en las citas de los dos autores mencionados, el uso de la palabra "crisis" no significa fomentar un espíritu catastrofista, y menos aún, derrotista. ${ }^{4}$ Más bien se pretende rescatar el sentido original del vocablo, que se refiere a una experiencia de incertidumbre profunda, en la cual lo que se había estado viviendo como garantizado y normal pierde vigencia, pero no se vislumbran aún los contornos de lo que está emergiendo para sustituirlo. Respecto a la clase de realidad que estudian las ciencias sociales y humanas y en la cual el futuro no es algo predeterminado, sino resultado de opciones todavía abiertas, el vocablo crisis evoca el verbo griego krinein, que tiene que ver con distinguir, valorar, juzgar, decidir y, por tanto, optar. Además, en muchas partes del mundo se observan también expresiones de tendencias opuestas a las fatales mencionadas: expe-

1 Se llevó al cabo con motivo de la celebración del 45o aniversario del Departamento de Antropología de la Universidad Autónoma Metropolitana-Iztapalapa los días 25 y 26 de febrero de 2020 en la Ciudad de México.

2 Véase también cómo caracteriza la situación en su "Breve introducción a los tres tomos" (Leyva Solano, 2018: 23-24).

3 De modo particularmente ácido el antropólogo británico-canadiense Christopher Hallpike, especializado en el estudio de sociedades primitivas, evolución social y derechos humanos, ha criticado la situación actual de la antropología sociocultural en su portal-e personal: "Mientras que la antropología sociocultural gusta describirse a sí misma como 'disciplina', en realidad ha abandonado cualquier semejanza con una disciplina intelectual, pues (ya) no posee un cuerpo coherente de teoría ni un conocimiento experto distintivo. En vez de ello, ha degenerado en una mezcolanza de tópicos efímeros..." (Hallpike, s. f.).

4 Empero, llama la atención que el diario El País informó el 27 de septiembre de 2017 que "la llegada de Trump convierte '1984' en superventas en EE UU”, y que el Festival Internacional de Cine de Venecia 2020 otorgó su segundo premio más importante a una película distópica, en la cual las desigualdades en México llevan en 2021 a conflictos sociales tales que desembocan en el establecimiento de un gobierno militar (La Jornada, 11 de septiembre de 2020 <https: / /www.jornada. com.mx/2020/09/11/espectaculos/a05n1esp>) [5 de febrero de 2021]. 
rimentos grandes y pequeños de una vida menos destructora de los recursos naturales a los que tienen derecho asimismo las generaciones venideras; intentos menores y mayores de reformar instituciones políticas, administrativas, educativas y demás mediante el desarrollo de principios democrático-participativos puestos a prueba en circunstancias novedosas; numerosas acciones solidarias a escala local, nacional y planetaria con quienes siguen excluidos del disfrute de los bienes socialmente generados; búsqueda de otras vías de desarrollo, incluso allá donde la ciencia domesticada predica la razón del Estado y la inexistencia de alternativas; surgimiento de exigencias de respeto a formas de vivir hace pocas generaciones todavía inexistentes, como las que tienen que ver con la edad, el género, la lengua materna; exploración de modelos de repartición de la riqueza socialmente producida, distintos de los mecanismos acostumbrados de la herencia, la especulación, el trabajo asalariado, la antigüedad alcanzada en un puesto, la capacidad de corromper, la multiplicación de necesidades creadas...

Apenas terminado el mencionado coloquio, se desplegó de repente y a gran velocidad en todo el país la pandemia causada por el novedoso coronavirus. Si bien ha contribuido a modificar los pesos relativos de algunos aspectos de la crisis arriba enlistados y a visibilizar mejor otros hasta entonces menos presentes en la opinión pública, es patente que ante todo los ha expuesto con mucha claridad como partes integrantes de una crisis civilizatoria. ¿O acaso no es síntoma de tal crisis que en una situación en la que se enfatiza una y otra vez la necesidad de algo tan simple como el frecuente lavado de manos tal regla no sea nada fácil de seguir, cuando tres de diez habitantes actuales del planeta ni siquiera cuentan con agua corriente en sus domicilios ${ }^{5}$ ¿No evidencia lo mismo la inmisericorde mercantilización de los servicios de salud y los sistemas hospitalarios en casi todo el mundo y la fuerte dependencia de medicamentos producidos en países lejanos, donde la tasa de explotación es aún mayor que en el propio? ¿Qué dice sobre el estado de la sociedad el precio de un cubrebocas y, en dado caso, de gel desinfectante para todos los miembros de una familia que tiene que sobrevivir con uno o varios salarios mínimos? ¿Y qué decir de las instituciones políticas, administrativas, educativas y empresas privadas que han estado entregando, sin problematización alguna, cantidades colosales de datos sobre las vidas, el pensamiento y los afectos de ciudadanos, académicos, estudiantes, pacientes, pasajeros, usuario y clientes a un puñado de empresas privadas que operan al margen de cualquier control democrático y cuyo modelo de negocio se basa precisamente en la recopilación de toda clase de informaciones personales?

Si bien en ámbitos relacionados con la atención a la salud y con la situación de diversas clases de víctimas de sus consecuencias físicas y socioeconómicas se han podido observar acciones innovadoras e incluso actos heroicos, es de igual modo cierto que buena parte de las ciencias sociales y humanas, en especial de las académicas, parecen haberse mantenido bastante al margen de las preocupaciones ciudadanas mayoritarias. ${ }^{6}$ También por ello, la invitación contenida en el nombre del evento conmemorativo del Departamento de Antropología parece ahora doblemente relevante.

Este texto, versión revisada y ampliada de la ponencia presentada en el coloquio conmemorativo mencionado y basado en varios trabajos anteriores, ${ }^{7}$ da la oportunidad de aportar a esta tarea la demostración de la semejanza intrínseca entre la tradición de búsqueda definitoria de los derechos humanos, su promoción planetaria y la defensa solidaria de las víctimas de su violación, y la antropología, ciencia social especializada en documentar y explicar la diversidad de los fenómenos socioculturales en el mundo. Para tal fin, se expone en el apartado subsecuente la concurrencia de los mismos dos aspectos teóricos semejantes en ambas tradiciones de pensamiento: la tensión entre lo local y lo global, y su carácter esencialmente procesual. Después se abordan de modo particular varios elementos de tipo utópico que se hallan en ellas. El comentario final hace una breve alusión a la presencia de esta temática en las universidades en las que se enseña antropología.

5 Según un comunicado de la Organización Mundial de la Salud del 18 de junio de 2019, "alrededor de 2200 millones de personas en todo el mundo no cuentan con servicios de agua potable gestionados de manera segura... y 3000 millones carecen de instalaciones básicas para el lavado de manos" (<https: / www.who.int/es/news-room/detail/ 18-06-2019-1 in-3-people-globally-do-not-have-access-to-safe-drinking-water-\%E2\%80\%93-unicef-who> [29 de agosto de 2020]). Véase también la noticia difundida por el periódico La Jornada, el 28 de agosto de 2020 con relación a un documento del Fondo de Naciones Unidas para la Infancia (Unicef): "En AL, 40\% de escuelas no cuentan con servicios para lavado de manos" <https: / / www.jornada.com.mx/2020/08/28/politica/003n3pol> [5 de febrero de 2021 ].

6 Una crítica aguda de los aportes intelectuales al análisis de la pandemia de la covid-19 la ha formulado el filósofo cubano Raúl Fornet-Betancourt (2020).

7 Me permito señalar sobre todo Krotz, 2003, 2004, 2008, 2013. Y aprovecho la oportunidad para un agradecimiento general a organizadores de y participantes en una buena cantidad de diplomados, conferencias y simposia sobre antropología jurídica durante los últimos años, en las cuales he podido presentar varias de las ideas aquí expuestas. También quisiera agradecer las observaciones de la(os) dictaminadora(es) del presente texto. 


\section{Características "paralelas" en antropología y derechos humanos}

En lo que sigue, entenderemos como antropología fundamentalmente la antropología sociocultural en su vertiente de ciencia básica y, por tanto, casi siempre académica, ${ }^{8}$ y como derechos humanos, la reflexión sistemática, a menudo denunciatoria, casi siempre propositiva, a veces acompañante de determinadas prácticas humanitarias y políticas en torno a tales derechos atribuidos desde 1948 en cada vez más países del mundo a toda persona humana por el simple hecho de serlo. Se trata de dos tradiciones de pensamiento diferentes, pero enlazadas de varias maneras.

Como se recordará de los orígenes de la antropología científica en el siglo xIx, muchos de los primeros antropólogos habían tenido una formación académica en derecho, que entonces era mucho más que el aprendizaje de una técnica de litigio. Sus especialistas más importantes se ocupaban del estudio de las ideas sobre, y de los mecanismos efectivos para la configuración de los fenómenos socioculturales de su época. Tal estudio incluía referencias constantes a etapas históricas y formas de organización social tan distantes como las del feudalismo, las llamadas cunas griega y romana de la historia europea o la vida rural en el interior y las periferias de los países europeos de su tiempo. A su vez, la recopilación y comparación de reglas de parentesco era materia prima para entender sistemas de derechos y obligaciones muy distintos de los que entonces estaban generando los emergentes Estados nacionales europeos. La historiografía de nuestra ciencia, que usualmente consigna algunas de las primeras sociedades etnológicas o antropológicas ubicadas en ciudades capitales europeas del siglo xIx, vinculaban el interés por inventariar la diversidad humana planetaria con la lucha contra la esclavitud (Tax, 1955: 321 -322). Como es sabido, la concepción constitutiva para la antropología de la igualdad esencial de todos los seres humanos y, en consecuencia, de la diferencia solamente de grado (evolutivo) de sus sociedades y culturas, tardó en afianzarse durante el siglo xIX a través de los largos debates entre monogenistas y poligenistas, prodarwinistas y antidarwinistas y, por ende, también racistas y antirracistas, proesclavistas y abolicionistas. Menos presente se suele tener que esta discusión ya se había iniciado tres siglos antes, a saber, en torno a los primeros contactos entre europeos y americanos, que Ángel Palerm (2010: 85) ha identificado acertadamente como uno de los puntos de partida de la antropología moderna, y donde le correspondió a Bartolomé de las Casas encabezar el desmontaje teórico y político del planteamiento-hegemónico todavía tres siglos después en la civilización noratlántica y reforzado de manera poderosa por la persistente imposición colonial- de la existencia de varias clases naturales de seres humanos. ${ }^{9}$ Por todo esto, la antropóloga holandesa Caroline Archambault (2018: 2) anota que "dado que la antropología ha sido la principal disciplina dedicada al estudio comparativo de la humanidad, resulta sorprendente e incluso irónico... que, según parece, la(os) antropóloga(os) han jugado un papel bastante marginal en los inicios y el desarrollo de los derechos humanos". Sin embargo, de igual forma es obvio que hace poco tiempo, la antropología ha recobrado una cierta presencia mundial en el debate con relación a aspectos empíricos y temas teóricos de los derechos humanos de los pueblos indígenas. ${ }^{10}$

8 Esta limitación no implica menosprecio alguno de la antropología profesional, donde hay importantes núcleos dedicados a la promoción de los derechos humanos, pero, como ha sido lamentado en diversas ocasiones, hoy en día no existen canales realmente funcionales a través de los cuales la reflexión sobre estas prácticas y la reflexión teórica y temática se articule con la antropología académica, que tiene una especie de monopolio sobre las publicaciones y los congresos y simposia (puede verse para esta problemática en México, Krotz y Reygadas, 2020). Por otra parte, la referencia principal a la antropología sociocultural no debe hacer olvidar los aportes de combinaciones pioneras de diferentes subdisciplinas antropológicas, tales como la llamada antropología forense latinoamericana (véase para esto Robledo Silvestre y Hernández Castillo, 2019).

9 Véase para esto el primer volumen de la historia de la etnología de Palerm (2010: 247) en la que constata que Bartolomé de las Casas "generó una polémica sobre el sistema colonial que está en su apogeo todavía en nuestros días". Si bien tal juicio se formuló en el marco de la entonces incipiente construcción de las teorías de la dependencia, sigue vigente para ramificaciones posteriores de dichas teorías, tales como el análisis del colonialismo interno. En vista de que la historiografía usual de la idea de los derechos humanos y de los intentos de convertirla en criterio fundamental para la creación de un orden social justo universal no suele traspasar los límites de la civilización noratlántica, y deja de lado, por ejemplo, los aportes latinoamericanos (Krotz, 2020a: 96-100), tal juicio podría convertirse en un interesante punto de partida para la reflexión de(s)colonial en proceso.

${ }^{10}$ Mientras que Leslie E. Sponsel (2000: 153) resalta en una enciclopedia antropológica la relevancia conceptual y práctica de la antropología para la teoría de los derechos humanos, la recientemente fallecida especialista en antropología jurídica y derechos humanos Sally E. Merry (2012: 105) señala que hacia fines del siglo pasado se sustituyó en antropología del derecho el interés por la temática teórica universalismo-relativismo por el interés por la práctica de los derechos humanos. Una muestra interesante del trabajo teórico necesario para la promoción práctica de los derechos humanos de los 
Esbozaremos en lo sucesivo dos características que comparten estas dos tradiciones de pensamiento e investigación.

\section{La tensión entre lo local y lo global}

Esta tensión puede conceptualizarse también como la tensión entre lo particular y lo universal, o entre lo específico y lo general, o entre lo diferente y lo común, o entre el o los casos únicos observados y el modelo explicativo. ${ }^{11}$

Durante mucho tiempo, y de manera señalada durante la llamada Guerra Fría, la razón principal de criticar e incluso rechazar la Declaración Universal de los Derechos Humanos de 1948 se ha basado en su uso como instrumento político por parte de países miembros de la Organización del Tratado del Atlántico Norte (OTAN), pues con frecuencia se ha manejado con hipocresía como parte de un manipulado procedimiento de "certificación" de gobiernos, preferentemente del Tercer Mundo, para presionarlos a tomar determinadas decisiones o medidas.

Poco a poco, en buena medida a causa de la creciente presencia de naciones independizadas en tiempos recientes en distintos escenarios mundiales y en la misma Organización de las Naciones Unidas (ONU), y en respuesta a los fracasos de las sucesivas "décadas de desarrollo" a partir de los años sesenta del siglo pasado, se ha hecho más presente otra perspectiva crítica, a saber, la acusación del "etnocentrismo" noratlántico de dicha idea y Declaración, que ha podido ser remediado sólo inicialmente mediante los Pactos Internacionales de Derechos Económicos, Sociales y Culturales y de Derechos Civiles y Políticos de 1966/1976, promovidos, por cierto, sobre todo por países del Sur global. Años después, la Conferencia Mundial de Derechos Humanos de Viena de 1993 visibilizó a nivel internacional la reticencia de algunos países de Asia a adherirse en los hechos a las normas supuestamente universales de los derechos humanos, argumentando la existencia de "valores asiáticos" diferentes de los supuestamente "occidentales" plasmados en la Declaración. ${ }^{12} \mathrm{Al}$ margen del ostensible uso político de esta posición por regímenes a todas luces autoritarios y represivos, se intensificó así un debate hasta la fecha inconcluso sobre las condiciones de posibilidad de un "universalismo culturalmente inclusivo" (Astorga, 2010: 487) con respecto a los derechos humanos. El polémico libro del politólogo estadounidense Samuel P. Huntington (2001, orig. en inglés 1996), que establece desde el punto de vista y en función de los intereses imperiales de Estados Unidos una regionalización cultural mundial, sirvió, a pesar de sus desvíos, para destacar con precisión el tema de la religión como elemento cultural nuclear. Como poco después lo demostró la destrucción del World Trade Center neoyorquino en 2001 (que, por cierto, impulsó muchísimo el debate sobre y a partir de dicho libro), las creencias religiosas deben ser consideradas elementos culturales e identitarios en extremo relevantes para la construcción planetaria de una idea compartida sobre el ser humano y sus derechos fundamentales, por ser más difícilmente "negociables" en la interacción con otros grupos sociales.

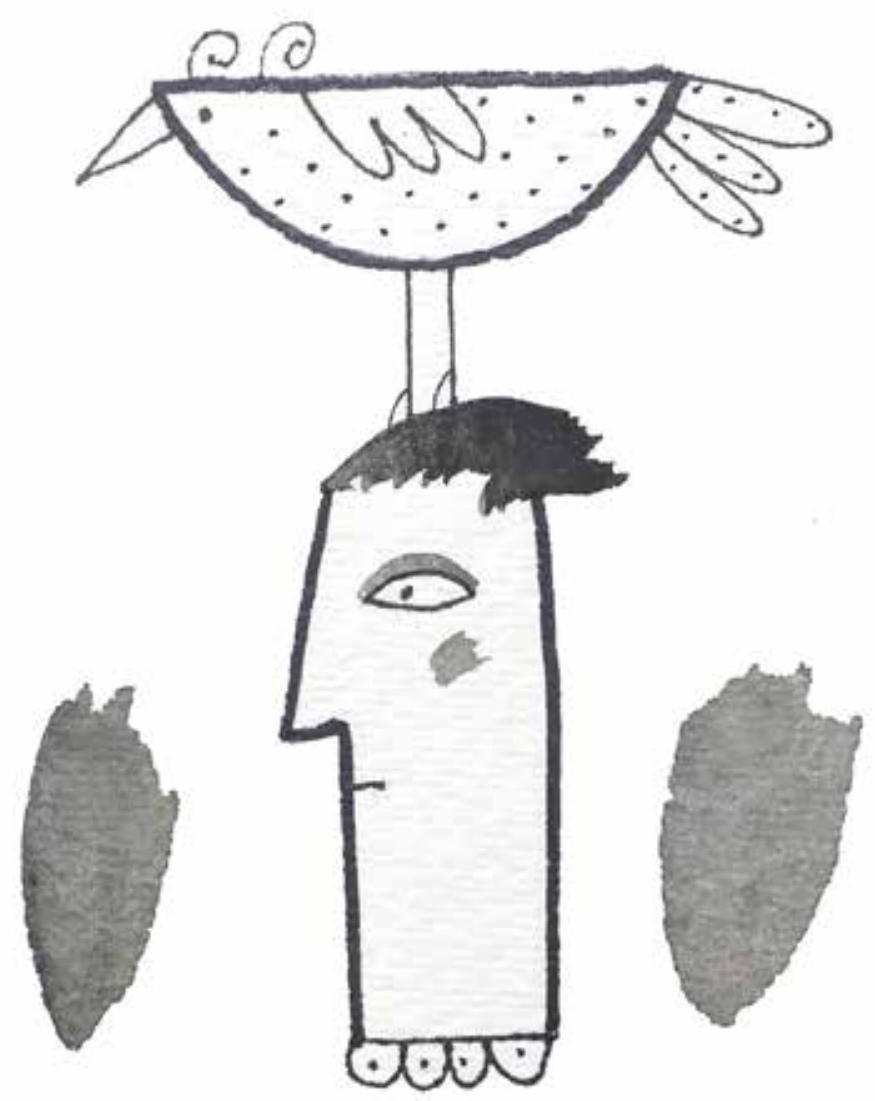

pueblos indígenas es la exposición de la problemática terminológica correspondiente en el apartado "Los escollos de la etnicidad y los conflictos étnicos" de Rodolfo Stavenhagen (2000: 23-46).

${ }^{11}$ Para el análisis de este último binomio sigue siendo esclarecedora la magistral explicación de Ángel Palerm (1972: 134140) sobre las características y las funciones de un modelo teórico frente a la particularidad empírica observada.

12 Véase, por ejemplo, Bell, 1996 y Chen, 2006. Tal situación contrasta con la aportación china a la preparación de la Declaración de 1948 (Krumbein, 2016). 
Por su parte, la antropología lleva desde sus inicios como disciplina la tensión mencionada, pues desde un principio fue una ciencia auténticamente glocal, combinando el estudio de lo particular con el interés por lo universal. Valga como testigo el muy conocido clásico de Lewis H. Morgan (1980), donde determinadas sociedades local y temporalmente circunscritas son estudiadas en sus propios términos y, al mismo tiempo, analizadas como representantes de una etapa evolutiva específica de la humanidad entera. Esto se aplica de igual modo a la famosa definición de cultura de Edward B. Tylor, que combina el análisis de las distintas etapas evolutivas con el examen de las características de toda la especie humana (Eriksen y Nielsen, 2013: 31). ${ }^{13}$

Por ello no puede extrañar que haya sido justo un antropólogo, el estadounidense Melville J. Herskovits, antiguo alumno de Franz Boas, quien se opusiera en 1947 a la propuesta de una declaración universal sobre derechos humanos, acerca de la cual una comisión de la recién fundada onu había consultado a la American Anthropological Association (AAA). En su exposición, que luego hizo suya la directiva de la AAA, ${ }^{14}$ Herskovits se pregunta: “¿Cómo puede la Declaración propuesta aplicarse a todos los seres humanos y no ser una declaración de derechos concebida exclusivamente en función de los valores dominantes en los países de Europa Occidental y de América?" (Herskovits, 2018: 24). ${ }^{15}$ Su argumentación desfavorable a tal propuesta se centra en la observación de que en ella se consagra el "respeto de la personalidad del individuo como tal y de su derecho al más completo desarrollo como miembro de la sociedad en la que vive. Ahora bien, en un orden mundial también es importante respetar la cultura de grupos humanos diferentes". Por lo que concluye que "el problema es formular una declaración de los derechos humanos que haga más que expresar simplemente el respeto del individuo como tal. También debe tener plenamente en cuenta al individuo como miembro del grupo social al que pertenece..." (Herskovits, 2018: 24).

Apenas una década después se dio una de las más conocidas confrontaciones teóricas sobre particularidad y universalidad en la antropología clásica y que se ocupó precisamente de un tema jurídico: el debate entre el antropólogo estadounidense Paul Bohannan y su colega sudafricano-británico Max Gluckman sobre semejanza y diferencia de sistemas normativos y argumentaciones jurídicas, similar, por cierto, al debate formalista-sustantivista en la antropología económica (Collier, 1995: 49-50; De la Peña, 2014: 63-66). ${ }^{16}$

Hoy día puede decirse que la discusión sobre y la promoción de los derechos humanos y el estudio antropológico de la sociedad humana desde la perspectiva de la alteridad comparten al menos dos problemáticas cognitivas clave.

Una es la llamada interculturalidad. Por lo común, la primera tradición mencionada se acerca a los otros de un modo focalizado en las ideas sobre ser humano, dignidad humana y derechos fundamentales; se interesa por las condiciones, las posibilidades y los límites de la convivencia pacífica y aborda sus temas con un interés predominantemente pragmático. La antropología, en cambio, se acerca a los otros externos e internos de un modo más comprehensivo y, en dado caso, ubicando el tema de los derechos humanos en el marco más amplio de organización social y universos simbólicos; ${ }^{17}$ o sea, su abordaje es más general que el de los especialistas en derecho e incluye de forma explícita la problemática epistémica. Desde hace poco, sobre todo en el Sur, se ha empezado a someter al mismo proceso de producción de conocimiento an-

${ }^{13}$ En este mismo sentido describe el antropólogo mayista estadounidense Evon Z. Vogt (1973: 13) la perspectiva compartida por los primeros antropólogos socioculturales que combina el interés por la diversidad de la especie humana con el interés por su historia común.

${ }^{14}$ El documento se halla reproducido en el número 4 del volumen 49 de la revista American Anthropologist (Executive Board, American Anthropological Association, 1947); extractos traducidos al castellano se publicaron en un número conmemorativo reciente de El Correo de la Unesco (Herskovits, 2018). El artículo de revisión de la antropóloga estadounidense Ellen Messer (1993) contiene más información. Para una mirada crítica sobre las posiciones posteriores de la AAA puede consultarse el artículo de la especialista estadounidense en derecho Karen Engle (2001).

${ }^{15}$ La relevancia de esta pregunta puede percibirse al recordar que la fundación de las Naciones Unidas sucedió cuando la mayoría de los seres humanos vivía todavía bajo régimen colonial. Al mismo tiempo llama la atención cómo también en aquel tiempo se usaba el término "América" sin especificación para referirse sólo a los Estados Unidos de (Norte-)América -tal y como sigue sucediendo en noticieros de todo el mundo, incluso en América Latina.

${ }^{16}$ No pueden discutirse aquí, pero vale la pena señalar las revisiones históricas sobre la relación entre antropología y derechos humanos centrados con amplitud en el tema de la contraposición relativismo-universalismo del recientemente fallecido antropólogo, especialista en culturas amazónicas, Terence S. Turner (1997) y del antropólogo jurídico Mark Goodale (2009).

${ }^{17}$ Vale, pues, a grandes rasgos lo que María Teresa Sierra (1998: 26) ha señalado con motivo del derecho indígena: "La perspectiva antropológica, a diferencia de la visión jurídica, no busca construir modelos de aplicación general, abstrayendo los contextos sociales, sino dar cuenta de la manera en que los sistemas jurídicos se encuentran inmersos en la cultura y en el poder". 
tropológico -reconocido como parte integrante de la cultura-a un examen intercultural, tanto en lo que se refiere a las relaciones Norte-Sur en las antropologías mundiales ${ }^{18}$ como a la inclusión más sustancial de los conocimientos socioculturales de los estudiados en el estudio, que reta todas las formas de colonialismo interno.

Parece pertinente señalar que ambas tradiciones se han dado cuenta de que el término "diálogo intercultural" es una metáfora tendiente a disimular la dificultad de la compleja tarea pendiente, la cual, lejos de limitarse a actos discursivos, incluye la dimensión afectiva e implica la revisión minuciosa y la reorganización pausada de hábitos, ideologías, instituciones y sistemas normativos propios, ${ }^{19}$ amén de la traducción paciente de ideas propias y propuestas a quienes han sido enculturados a dominios de "otros puntos de vista”, y viceversa.

La otra dimensión cognitiva involucrada, estrechamente relacionada con la que se acaba de esbozar, se refiere a la democracia, entendida aquí como una forma de vida colectiva que, a diferencia de muchos imaginarios populares y alegatos demagógicos, no excluye, sino que se basa en la diferencia político-cultural (más no en la desigualdad socioeconómica). O sea, se trata de un estilo de vida colectiva en el cual el desarrollo de conflictos y las múltiples estrategias para su definición, formalización, clasificación, evitación, agudización, distensión y solución son considerados y practicados como elementos constitutivos y no tratados como patologías. ${ }^{20}$ Sin embargo, la antropología ha documentado una enorme diversidad en el mundo en cuanto a conflictos reconocidos o desconocidos, permitidos o suprimidos, y de las instituciones aceptadas para abordarlos socialmente. Por consiguiente, es comprensible que en muchas partes, en especial en América Latina, se haya incrementado desde hace tiempo no sólo el número y la variedad de organizaciones no gubernamentales defensoras y promotoras de los derechos humanos, sino también de instancias académicas que se ocupan de una u otra manera de la antropología jurídica, la cual emergió en diferentes contextos de la antropología política. ${ }^{21}$

¿No resulta patente que las dos tradiciones de pensamiento, antropología y derechos humanos, podrían interactuar para enriquecerse mutuamente con sus resultados, tanto con respecto al llamado diálogo intercultural y a la promoción de la democracia como en la reflexión sistemática sobre los derechos humanos y los esfuerzos prácticos para consolidar su vigencia planetaria?

\section{El carácter procesual de la antropología $y$ de los derechos humanos}

A diferencia de imágenes populares muy difundidas, ni la ciencia antropológica ni la idea de los derechos humanos constituyen cuerpos de conocimientos fijos que sólo tendrán que ser descubiertos o construidos de una vez por todas por los expertos respectivos y luego "aplicados" adecuadamente. No pocas veces irrita incluso a aprendices y también a especialistas, y más aún, a burócratas, políticos, periodistas y los omnipresentes "analistas" su carácter procesual, que en ciertas etapas puede ser lineal, pero que por lo general es ramificado y lleno de callejones sin salida, fusiones y recomienzos.

Sin embargo, en el imaginario de mucha gente, las ciencias -al menos, las autonombradas "exactas" y "naturales"- se asemejan a construcciones levantadas de manera paulatina, resultado del esfuerzo acumulativo generación tras generación. Por lo que a veces estudiantes de las ciencias sociales y humanas se desesperan, sobre todo en el momento del proyecto de tesis, al tener que escoger entre conceptos y modelos distintos y hasta contrarios, sin que ello implique la abdicación de los ideales de objetividad y veracidad. De modo semejante, no pocos ciudadanos se desaniman, no sólo con respecto a los derechos fundamentales,

18 Por ejemplo, la antropóloga malasia Wazir Karim (1996: 116) formula observaciones vastamente compartidas en América Latina y el Caribe cuando se queja de que en el Lejano Oriente en la actualidad "la antropología se ocupa de la reproducción comercial de conocimiento local como recurso intelectual global" y "sirve en el contexto de sus "centralidades' europeas y americanas, para generar conocimiento social para el consumo de audiencias europeas y americanas". Desde luego, este tipo de observaciones se siguen dirigiendo también, como ya se comentó, a formulaciones y prácticas relacionadas con los derechos humanos.

19 Siguen siendo sugerentes las ideas del filósofo catalán-hindú Raimon Panikkar (1993) sobre la necesidad del "desarme cultural" cuando se entra a una relación intercultural desde una posición de poder.

${ }^{20}$ No puede comentarse aquí que tal forma de vida no es posible en condiciones de desigualdad socioeconómica tales que condenan a considerables segmentos poblacionales a la lucha diaria por la sobrevivencia y/o les niegan el acceso efectivo a los procesos políticos y culturales nacionales e internacionales.

${ }^{21}$ Una panorámica latinoamericana reciente de tales acercamientos la ofrece el antropólogo ecuatoriano Diego Iturralde (2014) y, en general, la antología organizada por la antropóloga chilena Milka Castro Lucic (2014); con anterioridad, ella ya había publicado una colección de estudios relacionados con la interculturalidad (Castro Lucic, 2004). 
por las en apariencia interminables y tan repetitivas discusiones jurídicas entre filósofos, abogados, legisladores y activistas. Esta sensación se incrementa al darse cuenta de que las polémicas no tienen punto final definitivo y que, además, cada acuerdo consensado o impuesto lleva por fuerza a nuevas discusiones, nuevos descubrimientos y nuevas propuestas.

Uno de los más importantes aciertos de la antropología científica naciente fue, sin duda, su concepción de la realidad social y cultural como una realidad en proceso, de manera más precisa, en proceso evolutivo. Es cierto que esta idea antropológica, preparada a inicios del siglo xIx por filósofos como Hegel y Comte y luego por los llamados socialistas utópicos y flanqueada después por los avances de las ciencias naturales y los esfuerzos de múltiples movimientos sociales y cambios políticos del siglo, tardó en ser aplicada a la misma antropología como parte integrante de la cultura noratlántica y como componente de agudos debates intelectuales y hasta conflictos políticos. Sin duda, el abandono de la idea de la evolución durante casi medio siglo en la antropología hegemónica contribuyó a este retardo. La reflexión sobre las propiedades de los "clásicos" en la antropología como en las demás ciencias sociales y humanidade ${ }^{22}$ constituye un buen camino para reforzar la imagen de la producción colectiva del conocimiento científico en vez de como un edificio construido piso por piso, como una red con variados y cambiantes canales y nudos de discusión que incluye la frecuente revisión detallada $\mathrm{y}$, en dado caso, incluso la reanudación de debates llevados al cabo tiempo atrás y en otras circunstancias sociohistóricas.

En el campo de los derechos humanos también ha habido cierta reticencia en aceptar el carácter procesual de su formulación, ya que no pocas veces se ha querido petrificar la Declaración de 1948 y negar su evolución posterior, que se ha expresado, entre otros y de modo especialmente significativo, en los dos pactos internacionales arriba mencionados y en la Declaración de la Asamblea de las Naciones Unidas sobre los Derechos de los Pueblos Indígenas de 2007. Tales documentos y las largas discusiones que antecedieron a sus respectivas aprobaciones, y que siguen dándose sobre su aplicación práctica, contienen lentos avances relativos a la concepción misma de la idea de los derechos humanos universales. A esto se agregan diversos complementos en función de la visibilización de grupos poblacionales particularmente vulnerables, y varias innovaciones derivadas de cambios sociales, tales como la declaración de 2010 sobre el acceso seguro al agua potable salubre y al saneamiento como derecho humano fundamental para el completo disfrute de la vida y de todos los demás derechos humanos. A su vez han surgido propuestas para definir con igual motivo, por ejemplo, el acceso a la electricidad como un derecho humano fundamental, sin el cual ya no se puede garantizar otros derechos clásicos relacionados con la comunicación, la educación y la cultura, y de modo creciente también con la participación política y social o el cuidado de la salud.

Asimismo, ha habido cambios en cuanto a los actores clave, pues el Estatuto de Roma de la Corte Penal Internacional, entrado en vigor en 2002, significa, a pesar de la denegación de su ratificación por parte de varias potencias mundiales, un avance importante hacia una vigencia más efectiva de los derechos humanos. Por su parte, la concentración de poder económico, político y simbólico en empresas como Google, Apple, Facebook y Amazon (GAFA), que parece haber aumentado muchísimo desde el inicio de la pandemia, la cual ha generado en muchos ámbitos sociales un fuerte impulso a la virtualización, ${ }^{23}$ podría intensificar el incipiente debate sobre las grandes empresas como responsables directas de la violación o vigencia de los derechos humanos, aparte de los Estados signatarios de las declaraciones y los convenios internacionales mencionados.

¿No es notorio cómo en ambos campos, derechos humanos y antropología, hay que atender de modo semejante etapas de surgimiento, consolidación y cuestionamiento de algo nuevo, que siempre inician con una "crisis" en el sentido arriba señalado, y donde

${ }^{22}$ Sobre los clásicos, véase la pequeña introducción al tema de Krotz y Llanes Salazar (2019) y la presentación del programa editorial multiinstitucional "Clásicos y Contemporáneos en Antropología" (García Acosta y Melville s. f.). No obstante, debe señalarse que estas iniciativas van a contracorriente de la llamada "nueva universidad" neoliberal, denunciada hace tiempo por Pablo González Casanova (2007) y, más recientemente, en Francia (Collectif des revues en lutte, 2020), y en la que campean ideas curiosas sobre modernidad, actualidad y vigencia, que incluso han llevado a que docentes universitarios tengan que defender en sus programas de estudio (controlados por empleados administrativos) la pertinencia de incluir títulos con más de dos décadas de antigüedad de haberse publicado...

${ }^{23}$ La virtualización es un buen ejemplo para demostrar la necesidad de la permanente "actualización" de la Declaración, pues hoy día relativamente pocas personas tienen "correspondencia" en el sentido del que habla su artículo 12 ("Nadie será objeto de injerencias arbitrarias en su vida privada, su familia, su domicilio o su correspondencia, ni de ataques a su honra o a su reputación. Toda persona tiene derecho a la protección de la ley contra tales injerencias o ataques."), pero por tratarse de situaciones relacionadas con los derechos humanos imposibles de considerar en 1948, poco se ha podido proceder contra la exhibición sin consentimiento de datos personales en la www o eliminar la difusión de información personal publicada por ignorancia o error. 
la meta está presente sólo en forma de contornos? Procesos donde hay que distinguir entre cambios cíclicos, no direccionales y evolutivos, aunque la meta -el conocimiento y la convivencia de la diversidad de sociedades humanas, la concepción de "ser humano" libre, igual y fraternal-sororal-todavía no ha podido ser definida con claridad. Y donde se nota que, a pesar de que aquí se habla únicamente de derechos humanos y antropología, se necesita de la confluencia de todas las disciplinas sociales y humanas, incluyendo la filosofía, en la que desde hace tiempo se ha discutido la existencia o no del avance evolutivo, también con relación a la moral y las artes.

\section{Elementos utópicos en los derechos humanos y la antropología}

En ocasiones, defensores y promotores de derechos humanos que trabajan por su irrestricta vigencia en el planeta o que exigen su respeto en algún asunto específico se topan con que su meta es calificada como "utópica". Con este epíteto usualmente se quiere indicar que, quienes persiguen tal meta, están "fuera de la realidad", que están soñando con circunstancias que no corresponden al mundo presente de los intereses económicos y de los poderes políticos y militares, que están persiguiendo una quimera, la cual, si bien suena simpática y hasta deseable, no deja de ser, por principio, irrealizable. El filósofo alemán Ernst Bloch, cuya obra entera ha estado dedicada a la utopía, hace notar en su Introducción tubinesa a la filosofía que la desvalorización de algo como "utópico" en "boca de hombres de negocio que se consideran especialmente listos" se ha vuelto una expresión corriente, "adornada con miedo ante el futuro como tal” (Bloch, 1973: 128).

Ahora bien, la Declaración de 1948 suele leerse como una serie de normas que, en dado caso completadas por otras más contenidas en los acuerdos complementarios antes mencionados, sirven como lista de comprobación para el examen de documentos, instituciones y medidas político-administrativas en todo el mundo, y/o como instrumento de legitimación de reclamos y denuncias del maltrato intolerable de individuos y grupos de personas.

Sin embargo, ¿no podría leerse el texto de la Declaración ${ }^{24}$ también de otra forma, dejándose inspirar por la primera consideración de su "preámbulo", que reza así: "Considerando que la libertad, la justicia y la paz en el mundo tienen por base el reconocimiento de la dignidad intrínseca y de los derechos iguales e inalienables de todos los miembros de la familia humana”? O sea, ¿no podría entenderse la Declaración como un despliegue de los rasgos esenciales que debería tener un orden social que correspondiera a las necesidades del ser humano como tal, pero no del ser humano aislado y abstracto, sino del ser humano que sólo lo es como integrante de la especie, tal y como se encuentra formulada en el primer artículo y explicitada en los siguientes cinco: "Todos los seres humanos nacen libres e iguales en dignidad y derechos y, dotados como están de razón y conciencia, deben comportarse fraternalmente los unos con los otros"?

Al procederse así, no se eliminaría necesariamente, pero se eclipsaría de momento la álgida discusión sobre la dignidad humana, sobre la esencia de lo humano y sobre la posible legitimación naturalista o sobrenatural de los llamados derechos humanos. Si bien estos temas y enfoques han sido materia tradicional de las antropologías filosóficas y teológicas, tales disciplinas siguen moviéndose todavía casi de manera exclusiva en los marcos culturales y teóricos de referencia noratlánticos y no han sido aún suficientemente "interculturalizadas" para el diálogo a nivel planetario $;^{25}$ por su parte, este diálogo intercultural, apenas iniciado, se encuentra todavía muy hipotecado por demasiados participantes a quienes su pasado colonial y su posición subordinada actual les dificulta una visión de un mundo futuro marcado por la colaboración y no por la imposición desde el poder imperial o el extremismo particularista. Por ello, podría ser más conveniente no abordar el tema de los derechos humanos desde el reconocimiento formal de atribuciones abstractas a los entes singularizados que componen la especie humana, sino desde el idear y de poner en práctica intentos de construir fraternal-sororalmente relaciones sociales que garanticen en las condiciones historias dadas a todos y a cada uno de quienes son siempre seres-humanos-en-sociedad, ${ }^{26}$ la misma posibilidad del máximo individualmente alcanzable de vida libre y plena.

En este sentido parece afirmar el especialista estadounidense en historia intelectual Samuel Moyn (2015: 14): "No es posible entender el surgimiento reciente y el poder contemporáneo de los derechos humanos sin

\footnotetext{
${ }^{24} \mathrm{El}$ texto de la Declaración ha sido reproducido y comentado hace poco por profesionales de diversas ciencias sociales en un texto organizado por el Colegio de Antropólogos de Yucatán (Llanes et al., 2018).

${ }^{25}$ Una introducción a la problemática desde una posición latinoamericana se halla en Salas Astrain, 2006.

${ }^{26}$ Desde el punto de vista antropológico habría que decirse con mayor presición que son siempre seres-humanos-en-unasociedad-entre-otras-sociedades.
} 
concentrarse en su aspecto utópico: la imagen de otro mundo mejor con dignidad y respeto, valores que se encuentran en la base de su atractivo, incluso cuando los derechos humanos parecen ocuparse de reformas lentas y graduales". Sin embargo, en su esbozo de la historia de los derechos humanos, reduce a estos últimos a su configuración moderna desarrollada desde mediados del siglo xx y destaca sus discontinuidades por lo que toca a lo que muchas veces se presenta de modo simplista en una visión lineal como sus antecedentes históricos directos (Moyn, 2015: 54-55).

Ernst Bloch, en cambio, ofrece una perspectiva dialéctico-discontinua y multilineal de la evolución de la idea de los derechos humanos. Por un lado, recalca que "el futuro que todavía no ha llegado se hace visible en el pasado, y el pasado vindicativo y heredado, transmitido y cumplido, se hace visible en el futuro" (Bloch, 1977: XVII). ${ }^{27}$ Por el otro, con respecto a una de las manifestaciones pioneras icónicas más conocidas en la historia europea, insiste que:

las tres palabras libertad, igualdad, fraternidad apuntan en esta dirección, en la dirección de una liberación que, al fin, vincule al hombre a sí mismo, a su singularidad susceptible de desarrollo. Con estas palabras se creyó que podía hacerse todo lo que nos afecta de un modo sano, libre, coincidente. Pero así mismo se pone de manifiesto que en ellas mismas y entre ellas no todo está concorde, sino que se hallan llenas de multivocidad. [...] Pero las tres palabras no hubieran podido ser objeto de tanto abuso si, ya antes, todo hubiera estado claro en ellas. Como es importante que veamos, antes de nada, que estas palabras

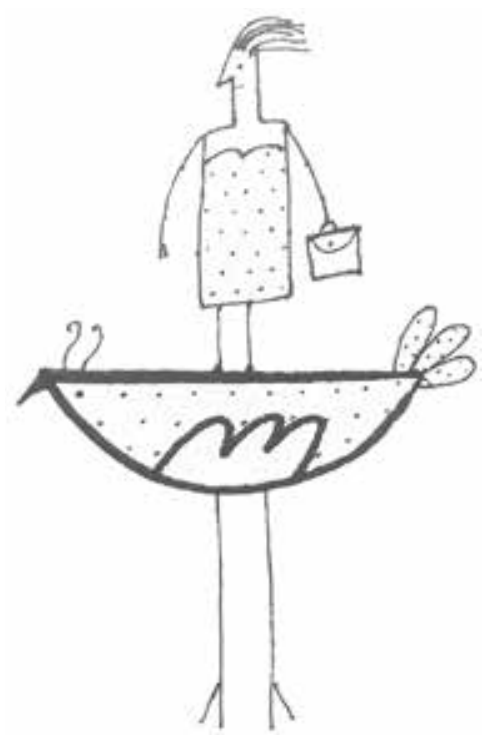

se hallan en sí mismas estratificadas, y su parte mejor no ha aflorado aún (Bloch, 1980: 156-157).

¿No sería éste el momento en el cual la antropología debería y podría recuperar los vínculos que tuvieron sus orígenes con el pensamiento utópico? Ángel Palerm dedicó la parte IV del primer volumen de su historia de la etnología sobre "los precursores", a "utópicos y rebeldes en la era de las revoluciones", desde el ya mencionado Bartolomé de las Casas hasta los revolucionarios franceses Louis Antoine de Saint-Just y François Babeuf, pasando, entre otros, por Tomás Moro y Vasco de Quiroga. Según Bloch, todos estos utópicos y los que les siguieron durante el siglo xix, en especial los llamados socialistas utópicos, carecían de una adecuada percepción de la realidad histórica -ésta fue posible sólo a partir y con base en el análisis sociocientífico de Marx y Engels.

Sin importar qué tanto se le quiere seguir a Bloch, lo interesante para nuestro tema es su insistencia en que para un cambio radical resulta necesaria la confluencia de dos fuerzas, las cuales llama de manera metafórica "corrientes", y que su obra fundamental, El principio esperanza, rastrea a lo largo de la historia europea. Una es la "corriente cálida", que analiza ante todo en los sueños diurnos, las artes, la religión, las rebeldías populares, los movimientos sociales y los intentos revolucionarios. Cuando se hace socialmente efectiva, se expresa en las protestas milenarias contra injusticia social y desigualdades, en las denuncias de explotación y opresión, denigración y jerarquías, en las manifestaciones de solidaridad y apoyo mutuo entre las víctimas del sistema social reinante, en la conmemoración de conatos de establecer el reino de la justicia y en el recuerdo mantenido vivo de tentativas fracasadas de lograr un mundo mejor. La "corriente fría", que de igual modo se hace presente en esta dilatada historia, se halla ante todo en la larga serie de indagaciones indignadas -hasta ahora sólo iniciales, fragmentarias- sobre las causas del desorden general establecido, los intentos de proyectar un orden alternativo basado en tal examen y los diseños de programas de acción para realizarlo que, sin embargo, han quedado frustrados precisamente por no estar articulados de forma correcta "con las tendencias y posibilidades sociales existentes” (Bloch, 1988: 262).

Ernst Bloch dedica un amplio apartado de su estudio a las llamadas novelas políticas o utopías sociales, ${ }^{28}$ ya que según él constituyen ejemplos de tales análisis, elaborados con sumo cuidado que se hallan

\footnotetext{
${ }^{27}$ Hay que hacer notar que el tema del pasado no liquidado y sus herencias atraviesa los tres tomos de El principio esperanza y, desde luego también el libro centenario inicial sobre Tomás Münzer (Bloch, 1968, orig. en alemán 1921).

${ }^{28}$ Una visión de conjunto de la tradición utópica se ofrece en Krotz, 1988.
} 
a lo largo de los siglos de la historia europea escrita: "La utopía social labora como una parte de la capacidad de asombrarse y de encontrar tan poco evidente lo dado, que sólo su transformación parece entrar por los ojos" (Bloch, 1979: 42). Pero, como ya se dijo, a pesar de importantes avances sucesivos, ${ }^{29}$ hasta Marx y Engels no se había encontrado la clave precisa para descifrar el fenómeno sociocultural en términos de relaciones causa-efecto y para poner en práctica eficaz el "imperativo categórico de subvenir a todas las relaciones en las cuales el hombre es un ser envilecido, humillado, abandonado, despreciado" (Marx, 1844). Sólo a principios del siglo xx, consolidada la ciencia social revolucionaria, y bastante crecida la protesta contra la explotación y el desprecio de la vida humana por el nuevo orden capitalista-industrial y sus devastaciones militares, ha podido pensarse con objetividad en un cambio profundo real, reconociendo, ahora sí y finalmente, "el itinerario" (Bloch, 1979: 41) histórico que tienen las revoluciones posibles: "Este último sueño social se encuentra ahora a la altura de la conciencia y se convierte así, penetrado de planificación, en un despertar social” (Bloch, 1979: 42).

En contraste con el optimismo de Bloch, el antropólogo haitiano Michel-Rolph Trouillot se ha expresado en una de sus últimas obras de manera bastante desilusionada sobre el siglo xx: "Fue el siglo de la esperanza pero, también, de las muertes violentas [...] Fue el siglo durante el cual las instituciones internacionales ganaron legitimidad pero, también, se institucionalizaron las disparidades internacionales" (Trouillot, 2011 : 52). Y sentencia: "La conexión entre la ciencia y la utopía está rota” (Trouillot, 2011: 136). Tan es así que, en el siglo xx, las más conocidas obras literarias apodadas "utopías" fueron de hecho su contrario, o sea antiutopías o distopías (Krotz, 2020b: 324-336).

Pero ¿no valdría la pena intentar volver a poner en contacto la corriente cálida representada sobre todo por quienes promueven la idea de los derechos humanos en un planeta socioculturalmente diverso y defienden de manera solidaria por doquier las víctimas de explotación, exclusión, ninguneo y maltrato, con la corriente fría del estudio antropológico de la diversidad existente, de la multiplicidad de concepciones del ser humano, de su dignidad y derechos, y de los posibles caminos hacia una sociedad en verdad humana?
Es evidente que tal intento tendría que realizarse en el marco de y, al mismo tiempo, podría ser un aporte importante a la de(s)colonización pendiente de las ciencias sociales y humanas sureñas, pues si bien ya hay pasos prometedores hacia unas antropologías del Sur que aportan a la antropología mundial desde el Sur, éstos son todavía iniciales y, como ya se ha señalado, también la historiografía de los derechos humanos sigue en lo fundamental nordocéntrica, al igual que el inventario de las corrientes cálidas y frías de la utopía. ${ }^{30}$

\section{Breve comentario final: derechos humanos, antropología, universidad}

No hay quien pueda hacer todavía un inventario de los estragos demográficos, psíquicos, económicos y político-culturales causados por el novedoso coronavirus. Tampoco puede predecirse si desembocará en una "nueva normalidad" realmente nueva. Empero, la frecuencia con que se usan verbos que inician con el prefijo "re", tales como recuperar, recobrar, reabrir, reiniciar, rescatar, reestablecer, restituir, reponer, hace temer que no en todas partes se esté pensando en aprovechar la visibilidad de la crisis civilizatoria acentuada por la pandemia, por ejemplo, para distinguir entre lo primario y lo secundario, entre lo esencial y lo superfluo, entre lo necesario para garantizar los derechos humanos de los más desfavorecidos por el modelo social vigente, y lo sobrante para quienes pueden visitar plazas comerciales con el único fin de "ver qué puede comprarse", entre lo imperioso para combatir el cambio climático antropogénico y lo funcional para incrementar aún más la tasa de ganancia, entre lo redituable en términos de informes bursátiles y lo indispensable para la alimentación sana y el cuidado de la salud de toda la ciudadanía.

¿No se manifiesta aquí una tarea tan obvia como urgente para las ciencias sociales y humanas? Claro está que hay que evitar confundir la enseñanza y la práctica académica de la antropología como ciencia de tipo básico con activismo político, trabajo social o alguna variante de tecnología aplicable a consumidores o electores. Tampoco se propone aquí reforzar la conversión hoy día en proceso de las universidades

\footnotetext{
${ }^{29}$ Para un examen de la fuerza socioanalítica de la obra clásica de Tomás Moro, puede verse Krotz, 2019.

${ }^{30}$ En el coloquio conmemorativo mencionado han aparecido varias pistas sugerentes para una reflexión sureña de(s)colonial sobre los derechos humanos como idea y práctica. Destacan entre ellas los estudios sobre la violencia extrema, como los realizados por Ricardo Falla sobre las masacres en Guatemala, no sólo para efectos de denuncia, sino también para poder entender las situaciones y acciones involucradas e incluso para encontrar preguntas relevantes para la comprensión de la violencia actual relacionada con la producción y el comercio de estupefacientes ilegales (Falla, 2019: 253-257), o los desarrollados por Myriam Jimeno y su equipo en Colombia, relativos al uso de la idea de los derechos humanos en la etapa posterior a la masacre (Jimeno Santoyo, Varela y Castillo, 2015: 186-191).
} 
en instituciones abocadas cada vez más a la formación técnica de egresados competentes para la ejecución de actividades profesionales subordinadas que supuestamente exige "el mercado”. Pero, ¿cómo proporcionar los instrumentos cognitivos de la antropología a quienes laborarán, como la mayoría de los egresados, en contextos institucionales complejos, sean éstos dependencias de la administración pública, departamentos especializados de empresas privadas, redes de organizaciones no gubernamentales, actores sociales y políticos interesados en conocer para fines muy diversos estructuras socioeconómicas y universos simbólicos? ¿No será el puente que, desde la ciencia básica practicada en la universidad, tendría que construirse y mantenerse con quienes interactúan orientada(os) por las teorías y metodologías antropológicas para fines de conocimiento con "objetos de estudio" que suelen pertenecer mayoritariamente a los que Eduardo Galeano (s. f.), quien en septiembre de 2020 celebraría su cumpleaños 80 , llamó:

Los nadies: los hijos de nadie,

los dueños de nada.

Los nadies: [...]

Que no son, aunque sean.

Que no hablan idiomas, sino dialectos.

$[\ldots]$

Que no hacen arte, sino artesanía.

Que no practican cultura, sino folklore.

Que no son seres humanos, sino recursos humanos.

Que no tienen cara, sino brazos..

¿No se manifiesta aquí uno de los elementos fundantes de nuestra disciplina? "La "capacidad para la cultura' es fundamentalmente la facultad de producir existencia social, y determina, por tanto, su significado y forma social. La 'diferencia', como principio de derechos humanos, es el resultado del desarrollo de esta capacidad. Es de esta forma un principio esencial de empoderamiento", señala el ya citado antropólogo estadounidense Terence Turner (2007: 60), mientras que el filósofo alemán Henning Hahn (2013) ha propuesto una "concepción política de los derechos humanos como lenguaje universal de crítica política".

Y ¿no se asoma aquí en la situación actual también un tema teórico tan central en las ciencias sociales y humanas latinoamericanas como el del "desarrollo"? Tema que, además, ha sido una constante en la disciplina, desde el paradigma evolucionista inicial, pasando por las polémicas inacabadas de todas las corrientes teóricas posteriores hasta el estudio de la evolución multilineal, de la ecología cultural y de la globalización -y tema clave en la búsqueda de salidas de la situación colonial persistente.

Pero, en vista de esta crisis civilizatoria, la cual no ha sido creada, sino sólo visibilizada mejor por la pandemia, ¿no tendrían que tomar las universidades, y en particular sus áreas de ciencias sociales y humanas, un papel más destacado y creativo en el debate sobre la situación y sus perspectivas, en la cual, como dice Bloch (1988: 260), "vivimos rodeados de posibilidades y no únicamente de cosas que existen". O sea, en una crisis en la cual hay que "repensar nuestro modo de vivir" ${ }^{31} \mathrm{Y}$ tratar de consolidar -o recobrar- lo que Claude Lévi-Strauss (1970: LIV) identificó alguna vez como la tarea de la antropología, o sea, el "esfuerzo que renueva y expía el Renacimiento por extender el humanismo a la medida de la humanidad".

\section{Fuentes}

Archambault, Caroline S.

2018 "Human Rights", en Hillary Callan (ed.), International Encyclopedia of Anthropology (ed. electrónica). John Wiley \& Sons, Hoboken $<$ doi org/ 10.1002 /9781118924396.wbiea 1907>

Astorga, Christina A.

2010 "Los derechos humanos desde una perspectiva asiática: el desafío de la diversidad y los límites de la universalidad", en Concilium, núm. 336, pp. 475-488.

Bell, Daniel A.

1996 "The East Asian Challenge to Human Rights: ReflectiononanEastWestDialogue", en Human Rights Quarterly, vol. 18, núm. 3, pp. 641-667.

BLOCH, ERNST

1968 Thomas Münzer, teólogo de la revolución, Ciencia Nueva, Madrid.

BLOCH, ERNST

1973 Tübinger Einleitung in die Philosophie I, 8aㅡ. ed., Suhrkamp, Fráncfort.

BLOCH, ERNST

1977 El principio esperanza, tomo I, Aguilar, Madrid. BLOCH, ERNST

1979 El principio esperanza, tomo II, Aguilar, Madrid. BlOCH, ERNST

1980 Derecho natural y dignidad humana, Aguilar, Madrid.

BlOCH, ERNST

1988 "Fragmentos sobre la utopía", en Esteban Krotz, Utopía, $2^{\text {a }}$ ed. corr. y ampl., Universidad Autónoma Metropolitana-Iztapalapa, México, pp. 257-269.

Castro Lucic, Milka (ED.)

2004 Desafíos de la interculturalidad: identidad, política y derecho, Universidad de Chile, Santiago.

Castro Lucic, Milka (ed.)

2014 Los puentes entre la antropología y el derecho: orientaciones desde la antropología jurídica, Universidad de Chile, Santiago.

${ }^{31}$ Para algunas ideas iniciales al respecto puede verse Krotz, 2020c. 
Collectif DES RevUes EN LUTTE

2020 "Ciencias en peligro, revistas en lucha", en $\mathrm{Ca}$ hiers des Amériques latines <http: / / journals. openedition.org/cal/9836> [24 de agosto de 2020].

Collier, Jane F.

1995 "Problemas teórico-metodológicos en la antropología jurídica", en Victoria Chenaut y María Teresa Sierra (coords.), Pueblos indígenas ante el derecho, Centro de Investigaciones y Estudios Superiores en Antropología Social/ Centro Francés de Estudios Mexicanos y Centroamericanos, México, pp. 45-76.

Chen, Albert H. Y.

2006 "Conclusion: comparative reflections on human rights in Asia”, en Randall Peerenboom, Carole J. Petersen y Albert H. Y. Chen (eds.), Human Rights in Asia: A Comparative Legal Study of Twelve Asian Jurisdictions, France and the USA, Routledge, Londres, pp. 487-516.

De la Peña, Guillermo

2014 "Costumbre, ley y procesos judiciales en la antropología clásica: apuntes introductorios". en Esteban Krotz (ed.), Antropología jurídica: perspectivas socioculturales en el estudio del derecho, $2^{\text {a }}$ ed., Anthropos/Universidad Autónoma Metropolitana-Iztapalapa, Barcelona y México, pp. 51-68.

ENGLe, KaREN

2001 "From Skepticism to Embrace: Human Rights and the American Anthropological Association from 1947-1999", en Human Rights Quarterly, vol. 23, núm. 3, pp. 536-559.

ERIKSEn, Thomas Hylland

Y FinN SIVERT NiELSEN

2013 A history of anthropology, 2 ${ }^{\mathrm{a}}$ ed., Pluto Press, Londres.

Escobar, Arturo

2018 "Presentación", en Xochitl Leyva Solano et al., Prácticas otras de conocimiento(s): entre crisis, entre guerras, vol. I, $2^{\text {a }}$ ed., Consejo Latinoamericano de Ciencias Sociales, Buenos Aires, pp. 9-11.

EXECUTIVE BOARD,

American Anthropological Association

1947 "Statement on Human Rights, submitted to the Commission on Human Rights, United Nations", en American Anthropologist, vol. 49, núm. 4, pp. 539-543.

FALLA, Ricardo

2019 "Antropología y violencia: una experiencia guatemalteca”, en Rosana Guber (ed.), Trabajo de campo en América Latina, vol. II, Campus/SB, Bogotá, pp. 251-260.

Fornet-Betancourt, Raúl

2020 "La pandemia de enfermedad por coronavirus, o la impotencia de los intelectuales", en Cultural, suplemento cultural de La Hora, 12 de junio <https: / issuu.com/lahoragt/docs / cultural 12-06-2020> [ $1^{\circ}$ de febrero de 2021].

Galeano, Eduardo

s. f. "Los nadies", en Red Internacional de Estudios Interculturales-Pontificia Universidad Católica del Perú <https://red.pucp.edu.pe/ridei/ noticias / los-nadies-por-eduardo-galeano/> [ 10 de febrero de 2021]

García Acosta, Virginia y Roberto Melville

s. f. "Clásicos y contemporáneos en antropología", <https://www.ciesas.edu.mx/publicacio nes/clasicos/libros/presentacion.pdf> [ $1^{\circ} \mathrm{de}$ febrero de 20211.

González Casanova, Pablo

2007 "La nueva universidad", en Pablo González Casanova, La universidad necesaria en el siglo XXI, 2a reimpr., México, Era, pp. 101-114 [2000].

GoOdAle, MARK

2009 Surrendering to utopia: an anthropology of human rights, Stanford University, Stanford.

Hallpike, Christopher

s.f. "The work and writing of Dr. C. R. Hallpike", en Hallpike.com <http: / / hallpike.com/ author.htm $>$ [25 de agosto de 2020].

Hahn, Henning

2013 "Human Rights as the universal language of critique: a political approach", en Zeitschrift für Menschenrechte, vol. 7, núm. 2, pp. 4258.

Herskovits, Melville

2018 "Derechos individuales y respeto de las culturas", en El Correo de la Unesco, octubrediciembre, pp. 24-26.

Huntington, Samuel P.

2001 El choque de civilizaciones y la reconfiguración del orden mundial, Paidós, Buenos Aires.

ITURRALDE, DiEGo

2014 "Utilidades de la antropología jurídica en el campo de los derechos humanos: experiencias recientes", en Milka Castro Lucic (ed.), Los puentes entre la antropología y el derecho: orientaciones desde la antropología jurídica, Universidad de Chile, Santiago, pp. 405-438.

Jimeno SANTOYO, MYRIAM,

DANIEL VARELA

y Ángela CASTILlo

2015 Después de la masacre: emociones y política en el Cauca indio, Universidad Nacional de Colombia/Instituto Colombiano de Antropología e Historia, Bogotá.

KARIM, WAZIR JAHAN

1996 "Anthropology without tears: how a 'local' sees the 'local' and the 'global", en Henrietta L. Moore (ed.), The Future of Anthropological Knowledge, Routledge, Londres, pp. $115-138$.

KROTZ, Esteban

1988 Utopía (2 ${ }^{\mathrm{a}}$ ed. corr. y ampl.), Universidad Autónoma Metropolitana-Iztapalapa, México.

Krotz, Esteban

2003 "Hacia una fundamentación ética del derecho a mantener y desarrollar una cultura propia", en América Indígena, vol. LIX, núm. 3, pp. 9-21.

KROTZ, EsteBAN

2004 "Antropología, derechos humanos y diálogo intercultural", en Revista de Ciencias Sociales, núm. 103-104, pp. 75-82.

KROTZ, EsteBAN

2008 "La fundamentación de la idea de los derechos humanos en contextos multiculturales", en Alteridades, año 18, núm. 35, pp. 9-20.

Krotz, Esteban

2013 "Utopía, antropología y derechos humanos", en Eduardo E. Parrilla Sotomayor (comp.), La utopía posible, vol. 1, Instituto Tecnológico de Monterrey, Monterrey, pp. 147-171.

KROTZ, EstebAN

2019 "La protoantropología de Tomás Moro: un re- 
descubrimiento a 500 años de la primera publicación de “Utopía”, en Revista de El Colegio de San Luis, nueva época, año IX, núm. 20, pp. 51-76.

Krotz, Esteban

2020a "América Latina a principios del siglo xxi: entre distopías y utopías", en En-Claves del Pensamiento, año XIV, núm. 28, pp. 86-109.

Krotz, Esteban

2020b La otredad cultural entre utopía y ciencia (3a reimpr.), Fondo de Cultura Económica/Universidad Autónoma Metropolitana-Iztapalapa, México.

KROtz, Esteban

2020c "Coronavirus: tres preguntas sobre nuestro modo de vivir", en Común, 1 de julio <https: / / www.revistacomun.com/blog/coronavirustres-preguntas-sobre-nuestro-modo-devivir $>$ [ 1 o de febrero de 2021].

KROTZ, Esteban

y RoDRigo Llanes SALAZAR

2019 “QQué es un clásico, por qué leerlo?”, en $R e$ vista de la Universidad Autónoma de Yucatán,

KROTZ, EsTEBAN vol. 34, núm. 274, pp. 18-24.

y LuIS BERNARDO REYGADAS

2020 “Hacia la desacademización de la antropología mexicana? Una idea para la discusión gremial y para el VI COMASE", en Blog del Colegio de Etnólogos y Antropólogos Sociales, A. C., 12 de noviembre <https://ceasmexico. wordpress.com / 2020/11/12/hacia-la-des academizacion-de-la-antropologia-mexicana una-idea-para-la-discusion-gremial-y-para-elvi-comas-e/> [ ${ }^{\circ}$ de febrero de 2021].

KrumbeIn, FrédÉRIC

2016 "Chinas Beitrag zur Allgemeinen Erklärung der Menschenrechte”, en Zeitschrift für Menschenrechte, vol. 10, núm. 1, pp. 60-77.

LÉvi-Strauss, Claude

1970 "Introducción", en Claude Lévi-Strauss, Antropología estructural, Ciencias Sociales, La Habana, pp. XXVII-LIV.

Leyva Solano, Xochitl

2018 "Breve introducción a los tres tomos", en Xochitl Leyva Solano et al., Prácticas otras de conocimiento(s): entre crisis, entre guerras, vol. I ( $2^{\mathrm{a}}$ ed.), Consejo Latinoamericano de Ciencias Sociales, Buenos Aires, pp. 23-34.

Llanes Salazar, Rodrigo et al. (COORDS).

2018 40/70:40Reflexiones desde Yucatána 70 años de la Declaración Universal de los Derechos Humanos, Colegio de Antropólogos de Yucatán/Universidad Autónoma de Yucatán/Proyecto Utopía, Mérida <https: / / cayacyucatan. wordpress.com/2018/12/10/40-70-40reflexiones-desde-yucatan-a-70-anosde-la-declaracion-universal-de-derechoshumanos / > [1 de febrero de 2021].

MarX, Carlos

1844 "Introducción para la crítica de la "Filosofía del derecho' de Hegel", en Marxists Internet Archive-Sección en Español <https://www. marxists.org/espanol/m-e/1844/introhegel.htm> [ $1^{\circ}$ de febrero de 2021].

Merry, Sally EnGle

2012 "Anthropology and law", en Richard Fardon et al. (eds.), The Sage Handbook of Social
Anthropology, vol. 1, Sage, Los Ángeles, pp. 105- 120.

Messer, Ellen

1993 "Anthropology and Human Rights", en Annual Review of Anthropology, vol. 22, pp. 221-249.

Morgan, Lewis H. 1980 La sociedad primitiva, 4⿳亠丷厂 ed., Ayuso, Madrid.

Moyn, Samuel

2015 La última utopía: los derechos humanos en la historia, Pontificia Universidad Javeriana, Bogotá

PAlerm, Ángel

1972 Agricultura y sociedad en Mesoamérica, Secretaría de Educación Pública, México.

PAlerm, Ángel

2010 Historia de la etnología: los precursores, $1 \stackrel{\text { a }}{\text { re }}$ impr.,Universidad Iberoamericana, México.

PANIKKAR, RAIMON

1993 Paz y desarme cultural, Sal Terrae, Santander.

Robledo Silvestre, Carolina

y Rosalva Aída Hernández Castillo

2019 "Diálogos entre la antropología social y las ciencias forenses", en Abya-Yala: Revista sobre acceso a la justicia y derechos en las Américas, vol. 3, núm. 2, pp. 7-23.

SAlas Astrain, Ricardo

2006 Ética intercultural: ensayos de una ética discursiva para contextos culturales conflictivos. (Re-)Lecturas del pensamiento latinoamericano, Abya-Yala, Quito.

Sierra, María Teresa

1998 "Autonomía y pluralismo jurídico: el debate mexicano", en América Indígena, vol. LVIII, núm. 1-2, pp. 21-48.

Sponsel, Leslie E.

2000 "Derechos humanos", en Thomas Barfield (ed.), Diccionario de antropología, Siglo xxi editores, México, pp. 152-153.

Stavenhagen, Rodolfo

2000 Conflictos étnicos y Estado nacional, Siglo xxI editores/Instituto de Investigaciones de las Naciones Unidas para el Desarrollo, México.

TAX, Sol

1955 "The integration of anthropology", en Yearbook of Anthropology, 1955, The University of Chicago Press, Chicago, pp. 313-328.

Trouillot, Michel-Rolph

2011 Transformaciones globales: la antropología y el mundo moderno, Universidad del Cauca/ CEso-Universidad de los Andes, Popayán y Bogotá.

Turner, Terence S.

1997 "Human Rights, Human Difference: Anthropology's contribution to an emancipatory cultural politics", en Journal of Anthropological Research, vol. 53, núm. 3, pp. 273-291.

Turner, Terence S.

2007 "Derechos humanos", en Ascensión Barañano, José L. García, María Cátedra y Marie J. Devillard (eds.), Diccionario de relaciones interculturales: diversidad y globalización, Editorial Complutense, Madrid, pp. 54-62.

Vogt, Evon Z.

"The history of cultural anthropology", en John J. Honigmann (ed.), Handbook of Social and Cultural Anthropology, Rand McNally, Chicago, pp. 1-88. 